Supporting Information

\title{
Electrochemical Aptasensor for Ultralow Fouling Cancer Cell Quantification in Complex Biological Media Based on Designed Branched Peptides
}

\begin{abstract}
Nianzu Liu ${ }^{\dagger}$, Jingyao Song ${ }^{\dagger}$, Yanwei Lu ${ }^{\dagger}$, Jason J. Davis ${ }^{\ddagger}$, Fengxian Gao ${ }^{\dagger}$, Xiliang Luo ${ }^{\dagger, *}$
$\dagger$ Key Laboratory of Optic-electric Sensing and Analytical Chemistry for Life Science, MOE; Shandong Key Laboratory of Biochemical Analysis; Key Laboratory of Analytical Chemistry for Life Science in Universities of Shandong; College of Chemistry and Molecular Engineering. Qingdao University of Science and Technology, Qingdao 266042, PR China.

$\$$ Department of Chemistry, University of Oxford, Oxford OX1 3QZ, United Kingdom.
\end{abstract}

\section{List of Supporting Infromation:}

S-I. Investigation of the newly designed peptide.

S-II. Characterization of the developed biosensing interfaces.

S-III. Antifouling ability of different surfaces.

S-IV. Optimization of sensing conditions.

S-V. Comparison with other reports.

S-VI. Stability and regenerability of the biosensor. 
S-I. Investigation of the newly designed peptide.
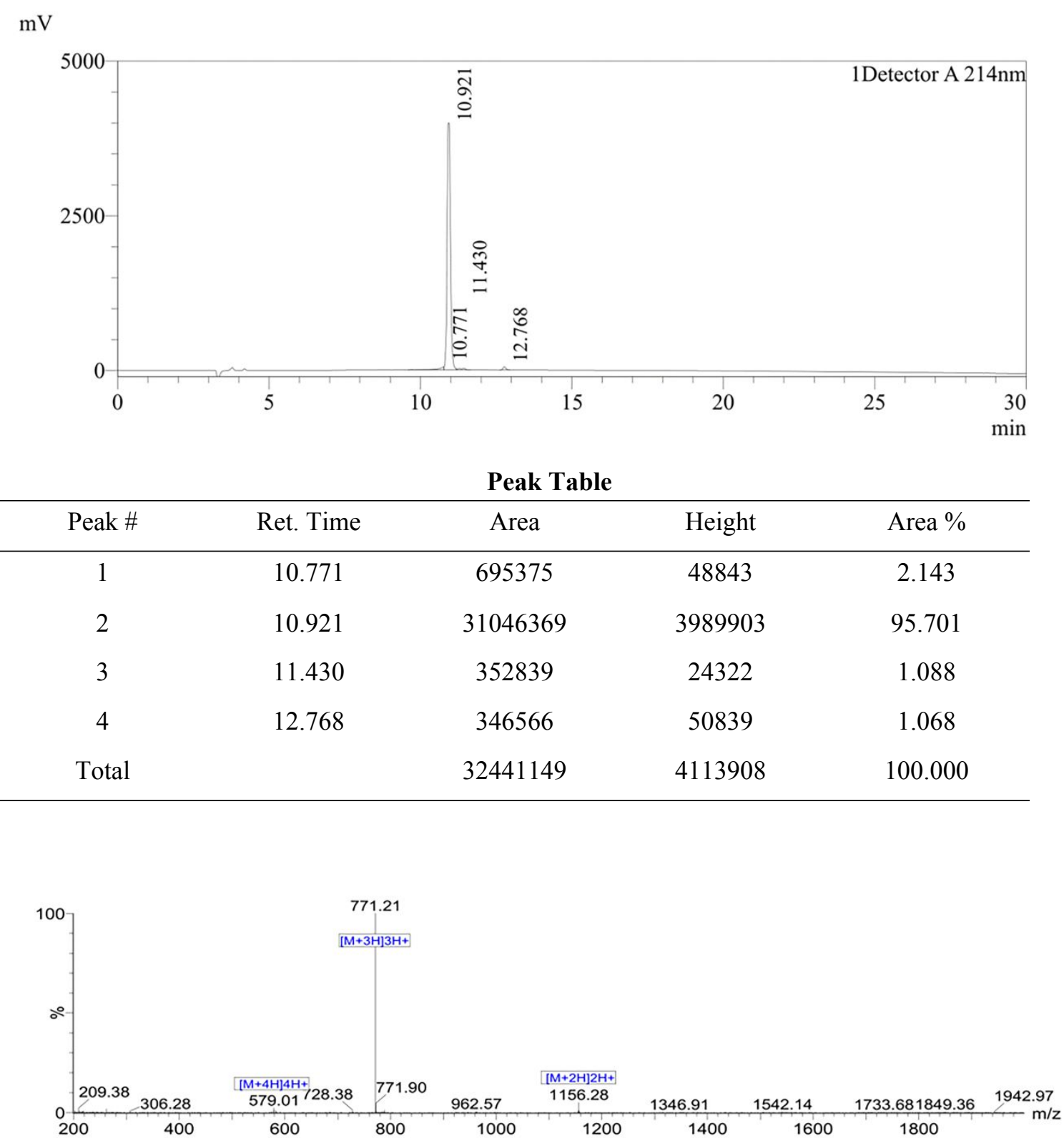

Figure S1. Chromatogram (top) and mass Spectrum (bottom) of branched peptide. 


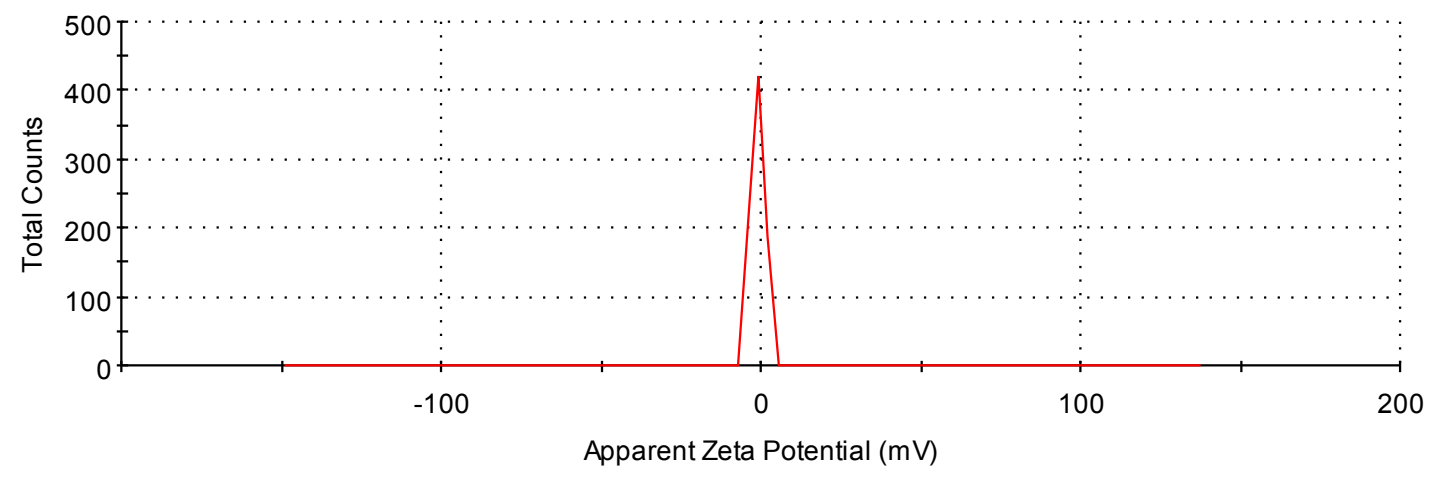

Figure S2. Zeta potential of the branched peptide.

\section{S-II. Characterization of the developed biosensing interfaces.}

Scheme S1. The process of covalent immobilization of peptides and aptamers onto

\section{PANI film.}

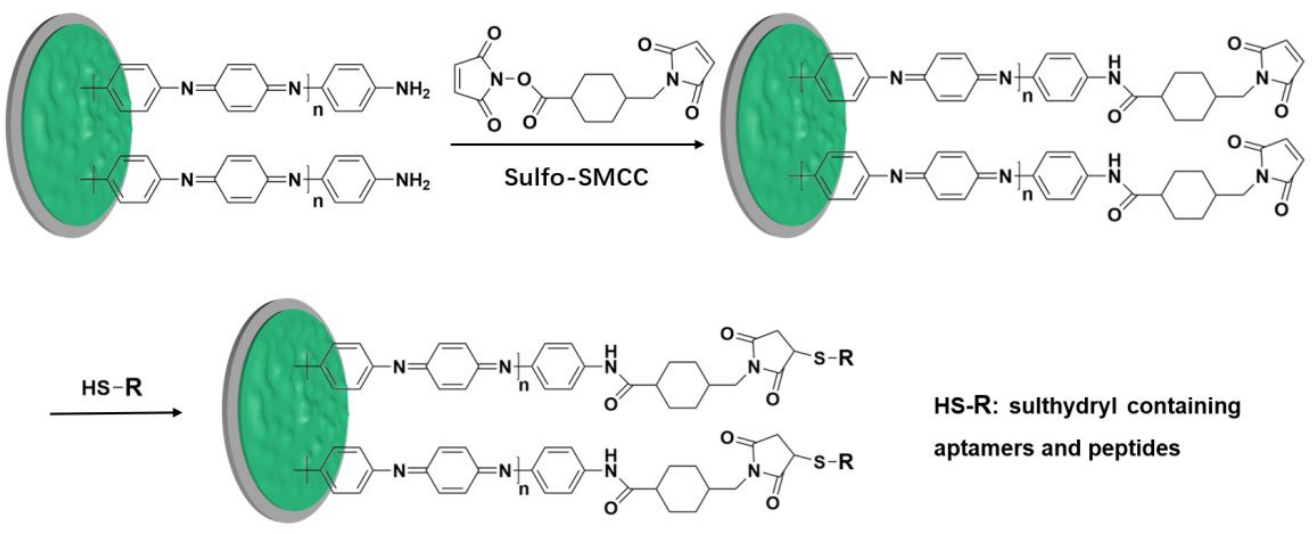


Table S1. Static water contact angles of different surfaces.

\begin{tabular}{cccc}
\hline \multirow{2}{*}{ Test points } & \multicolumn{3}{c}{ Contact angle $\left(^{\circ}\right)$} \\
\cline { 2 - 4 } & Bare GCE & PANI & peptide/PANI \\
\hline 1 & 47.70 & 56.07 & 20.94 \\
2 & 47.02 & 55.74 & 21.53 \\
3 & 47.69 & 55.38 & 21.31 \\
Average & $47.47 \pm 0.4$ & $55.73 \pm 0.3$ & $21.26 \pm 0.3$ \\
\hline
\end{tabular}

a)

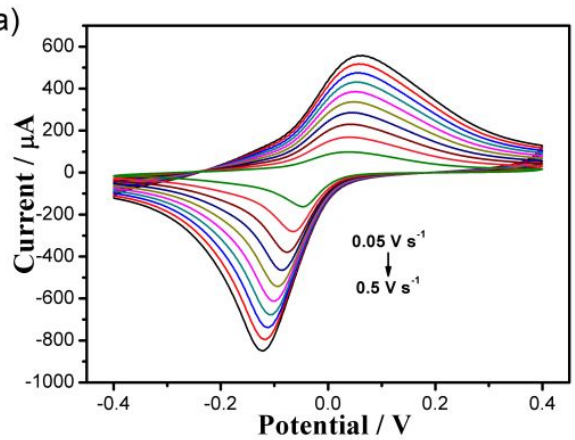

c)

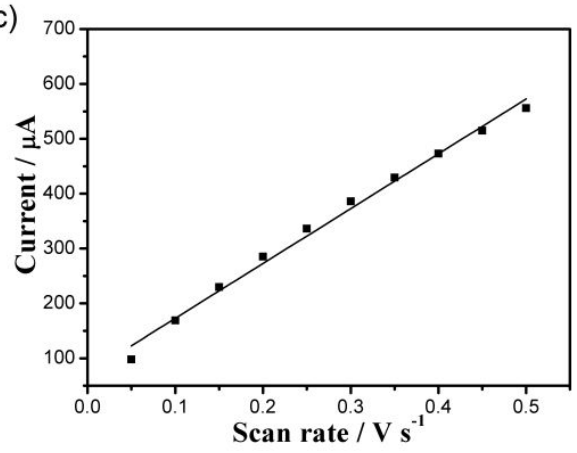

b)

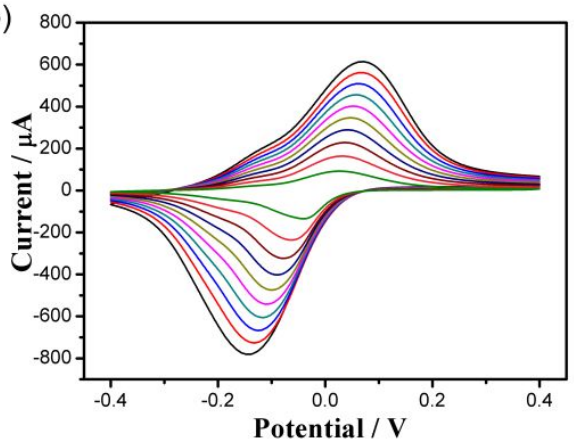

d)

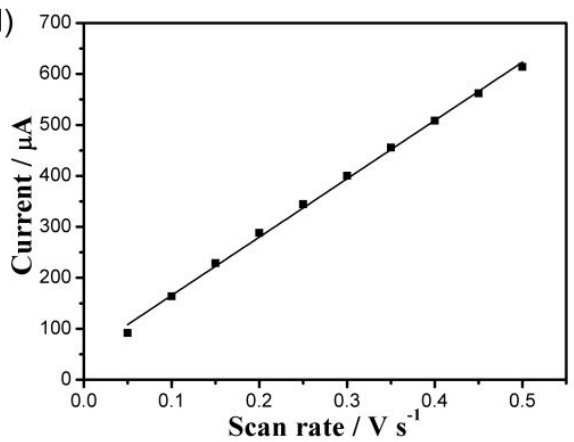

Figure S3. CVs of PANI (a) and peptide-aptamer/PANI (b) coated electrodes in PBS (0.2 $\mathrm{M}, \mathrm{pH} 7.4)$ at a scan rate of: $0.05,0.10,0.15,0.20,0.25,0.30,0.35,0.40,0.45$ and 0.50 $\mathrm{V} / \mathrm{s}$, respectively. Linear relationship of PANI/GCE (c) and peptide-aptamer/PANI/GCE (d) between the cathodic peak currents and the scan rate $(\mathrm{C}: \mathrm{I} / \mu \mathrm{A}=72.9+999.3 \mathrm{v}$, $\left.\left.\mathrm{R}^{2}=0.991\right), \mathrm{D}: \mathrm{I} / \mu \mathrm{A}=51.0+1144.5 \mathrm{v}, \mathrm{R}^{2}=0.998\right)$. 


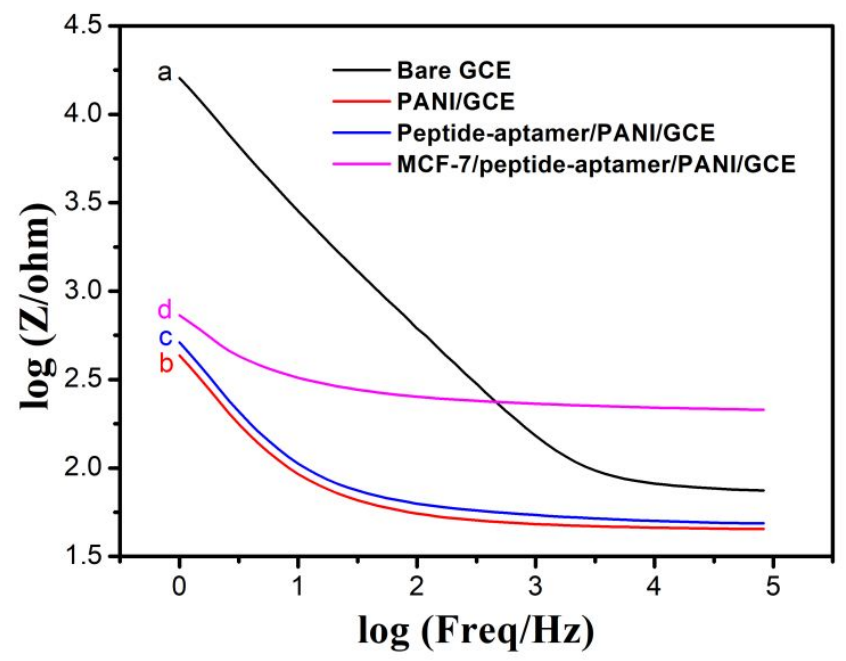

Figure S4. Impedance curves of non-Faradaic EIS Bode plots of a) the bare GCE, b) PANI/GCE, c) peptide-aptamer/PANI/GCE, d) MCF-7/peptide-aptamer/PANI/GCE in PBS (0.2 M, pH 7.4).

\section{S-III. DPV assessed antifouling character.}

a)

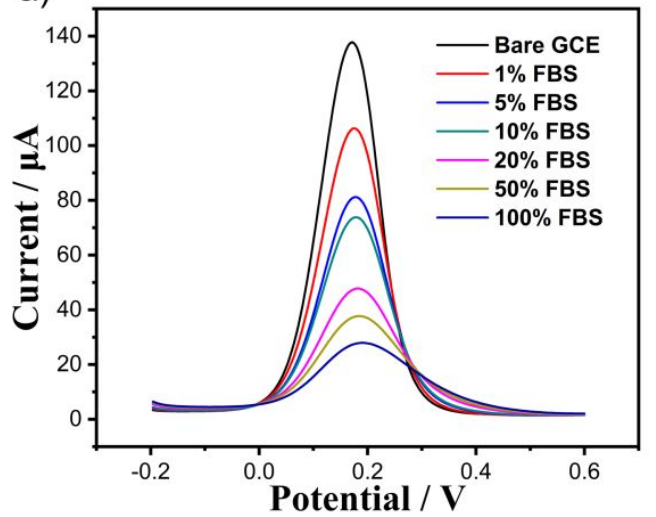

b)

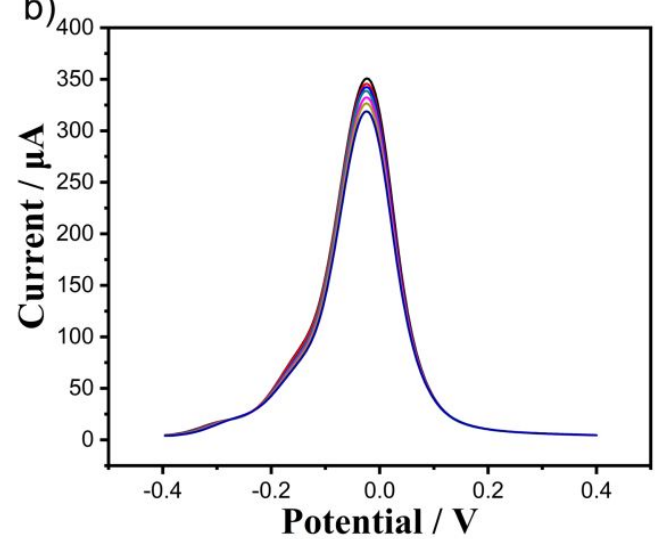

Figure S5. Representative DPV responses of the bare GCE (a) and peptide/PANI/GCE (b) for FBS samples of different concentrations (V/V). 


\section{S-IV. Optimization of the experimental conditions.}

In order to fabricate the optimal sensing protocol, several key experimental parameters, such as the peptide concentration, aptamer concentration, associated immobilization times and MCF-7 cell incubation times were investigated.

Influence of peptide concentration. Peptide concentrations showed a significant effect on fouling as analysed by incubation with $20 \% \mathrm{FBS}$, being optimized at $1 \mu \mathrm{M}$ (Figure S6a).

Influence of aptamer concentration. The concentration of aptamers showed significant effect on sensitivity of analytical response to MCF-7 cells with this (signal suppression) reaching a maximum value at $1 \mu \mathrm{M}$ aptamer (Figure S6b).

Influence of immobilization time. At a fixed concentration of peptides $(1 \mu \mathrm{M})$ and aptamers $(1 \mu \mathrm{M})$, the immobilization of peptides and aptamers reached saturation at 60 $\min ($ Figure S6c).

Influence of MCF-7 cells incubation time. In order to achieve the optimum capture time, the cell capture kinetics was investigated. The electrode was incubated with MCF-7 cells solution for varied time and the DPV signal was recorded accordingly. It can be clearly observed that the current change increased with the increasing of the incubation time and reached a maximum at $60 \mathrm{~min}$ as shown in Figure S6d, indicating that the binding achieved equilibrium. 

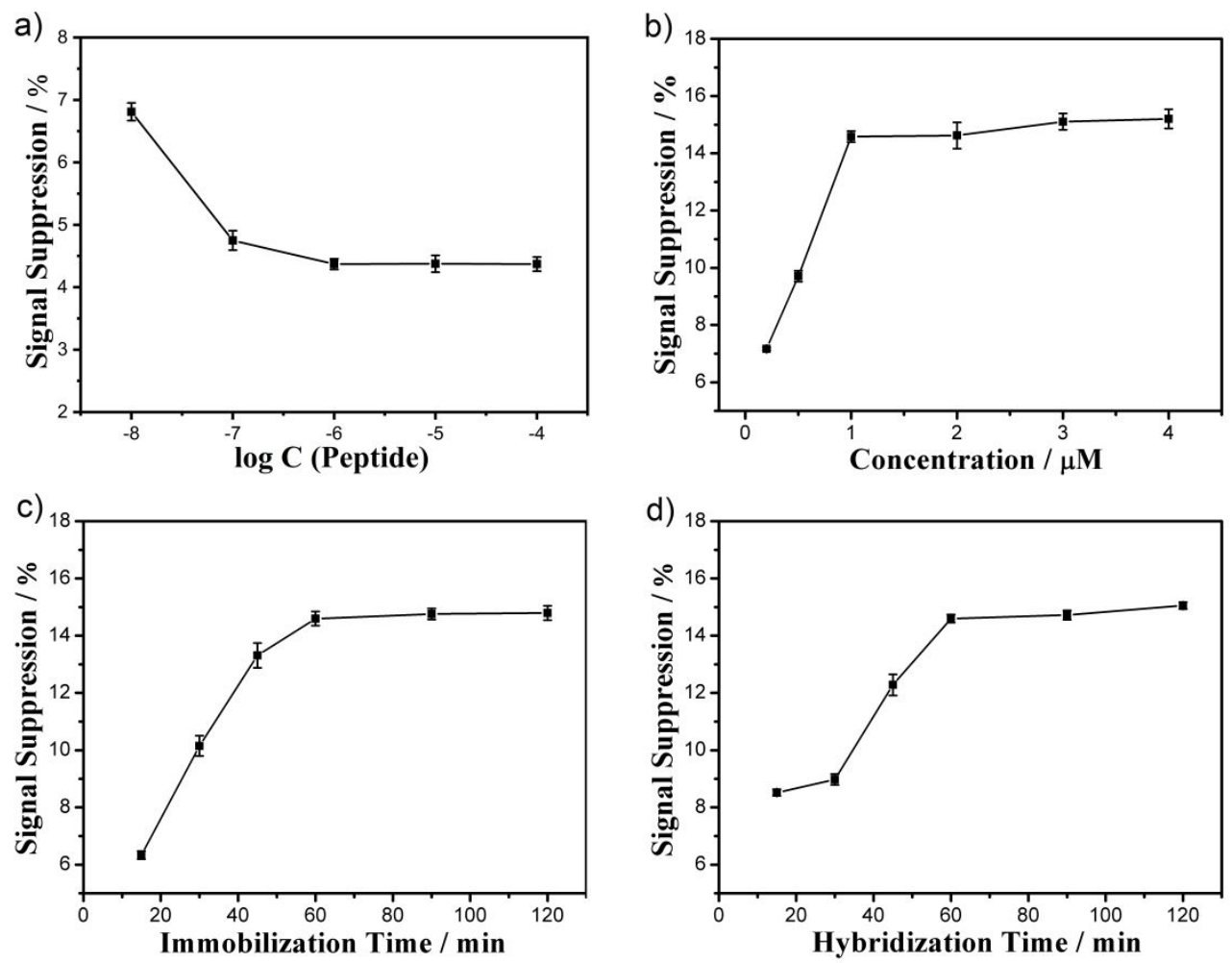

Figure S6. Effects of the (a) branched peptide concentration, (b) aptamer concentration, (c) immobilization time and (d) hybridization time on the DPV responses of the electrochemical biosensor toward $10^{4}$ cells $/ \mathrm{mL}$. Error bars represent the standard deviations of three repeated determinations $(n=3)$. 


\section{S-V. Comparison with other reports.}

Table S2. Comparison of sensing performance for the MCF-7 cells detection.

\begin{tabular}{|c|c|c|c|c|}
\hline Detection method & Material used & $\begin{array}{c}\text { Linear range } \\
\text { (cells/mL) }\end{array}$ & $\begin{array}{l}\text { Detection limit } \\
(\text { cells } / \mathrm{mL})\end{array}$ & Ref. \\
\hline ICP-MS & Magnetic beads & $2 \times 10^{2}-1.2 \times 10^{4}$ & 81 & 1 \\
\hline Colorimetric & $\mathrm{PtNPs} / \mathrm{GO}$ & $2.5 \times 10^{2}-8.0 \times 10^{3}$ & 125 & 2 \\
\hline Photoelectrochemistry & $\mathrm{NaYF} 4: \mathrm{Yb}, \mathrm{Er} / \mathrm{TiO} 2 / \mathrm{CdTe}$ & $10^{3}-10^{5}$ & 400 & 3 \\
\hline ECL & AuNPs/PANI & $10^{2}-10^{6}$ & 20 & 4 \\
\hline ECL & Con A@Au-C3N4 & $10^{2}-10^{6}$ & 150 & 5 \\
\hline Photoluminescence & QDs/SiO2 & $5 \times 10^{2}-10^{4}$ & 85 & 6 \\
\hline LSPR & Gold nanorods & $10^{2}-10^{5}$ & 100 & 7 \\
\hline SPR & $\mathrm{NiO} N \mathrm{NP}$ & $5 \times 10^{2}-4 \times 10^{3}$ & 136 & 8 \\
\hline ECL & Con A@AuNPs & $5 \times 10^{2}-5 \times 10^{5}$ & 150 & 9 \\
\hline Electrochemistry & Peptide-aptamer/PANI & $50-10^{6}$ & 20 & This work \\
\hline
\end{tabular}


S-VI. Stability and regenerability of the biosensor.
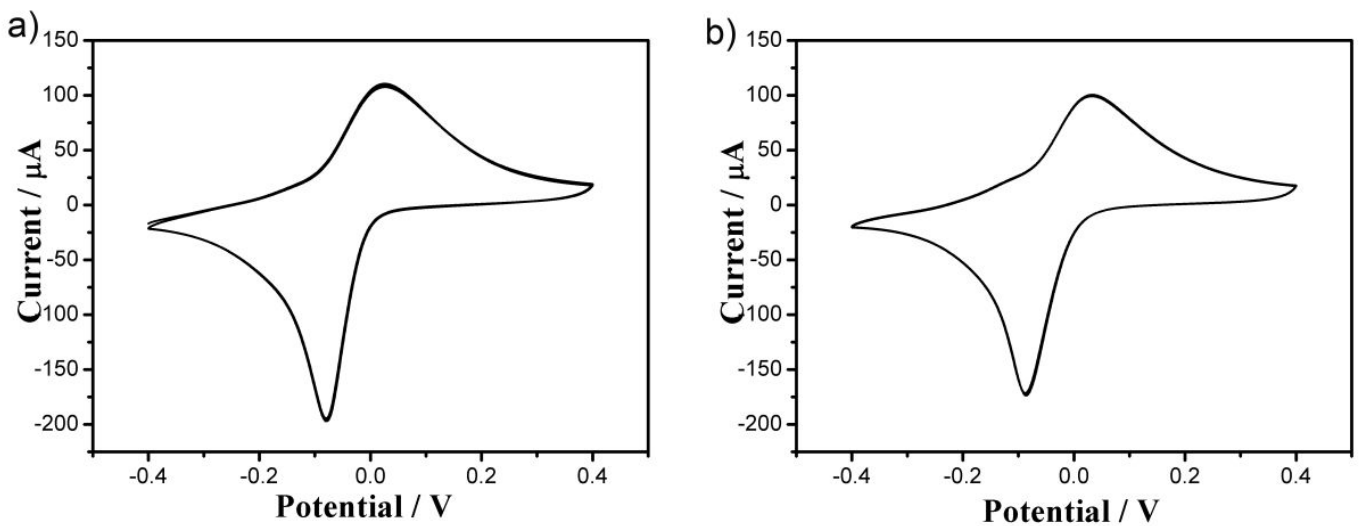

Figure S7. Representative assessment of interfacial stability (a: PANI/GCE, b: peptideaptamer/PANI/GCE) with $\mathrm{CV}$ at a scan of $0.1 \mathrm{~V} / \mathrm{s}$ in $\mathrm{PBS}(0.2 \mathrm{M}, \mathrm{pH} 7.4)$.

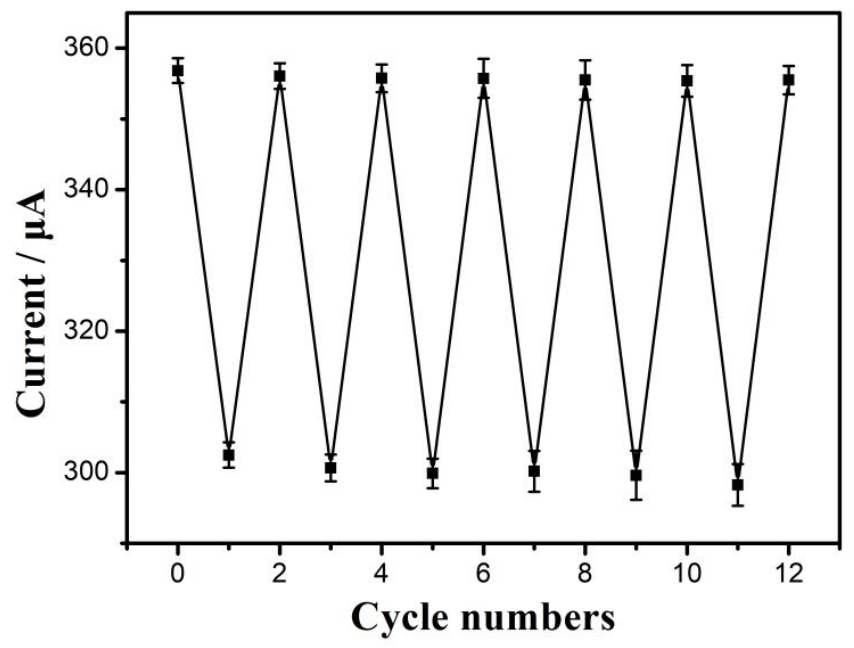

Figure S8. The regenerability of the peptide-aptamer/PANI modified electrode for MCF7 cells detection with the concentration of $10^{4}$ cells $/ \mathrm{mL}$. Error bars represent the standard deviations of three repeated determinations $(n=3)$. 


\section{References:}

(1) Yang, B.; Chen, B.; He, M.; Yin, X.; Xu, C.; Hu, B. Anal. Chem. 2018, 90, 2355-2361.

(2) Zhang, L.-N.; Deng, H.-H.; Lin, F.-L.; Xu, X.-W.; Weng, S.-H.; Liu, A.-L.; Lin, X.-H.; Xia, X.-H.; Chen, W. Anal. Chem. 2014, 86, 2711-2718.

(3) Wang, K.; Zhang, R.; Sun, N.; Li, X.; Wang, J.; Cao, Y.; Pei, R. ACS Appl. Mater. Interfaces 2016, 8, 25834-25839.

(4) Zhou, B.; Qiu, Y.; Wen, Q.; Zhu, M.; Yang, P. ACS Appl. Mater. Interfaces 2017, 9, 2074-2082.

(5) He, Y.; Li, J.; Liu, Y. Anal. Chem. 2015, 87, 9777-9785.

(6) Hua, X.; Zhou, Z.; Yuan, L.; Liu, S. Anal. Chim. Acta 2013, 788, 135-140.

(7) Li, Y.; Zhang, Y.; Zhao, M.; Zhou, Q.; Wang, L.; Wang, H.; Wang, X.; Zhan, L. Chem. Commun. 2016, 52, 3959-3961.

(8) Jia, S.; Li, P.; Koh, K.; Chen, H. Microchim. Acta 2016, 183, 683-688.

(9) Zhang, L.; Wang, Y.; Tian, Q.; Liu, Y.; Li, J. Biosens. Bioelectron. 2017, 89, 1013-1019. 